\title{
Investigating the Elements of Identity and the Process of Learners' Identification in the Fundamental Reform Document of Education: A Qualitative Study
}

\author{
Ehsan Mohammadinejad, Rahman Sahragard* \\ Department of Foreign Languages and Linguistics, Faculty of Literature and Humanities, Shiraz University, Shiraz, Iran \\ * Corresponding author's Email: rahman.sahragard@gmail.com
}

\begin{abstract}
Due to the idea of Islamization of humanities after the Islamic revolution in Iran, the concept of identity found new dimensions in the eyes of revolutionary policymakers and a sense of skepticism gradually grew regarding the impact of common educational policies on shaping learners' identity. Therefore, the discovered threat was responded by designing local regulatory plans such as the Fundamental Reform Document of Education (FRDE) to meet various ends among which planning for shaping learners' identity was the most prominent one. Thus, this study employed a qualitative approach and used techniques based on content analysis and grounded theory to study how identity is envisioned in FRDE, using MAXQDA software. FRDE was analyzed, then extracted items were coded and categorized in different affinities and finally five main themes appeared as the model of practicing national identity in FRDE namely a) The Nationwide b) The Islamic c) The Social d) The Individual and, e) The Global. Each of these levels is composed of different components, which explain the model of practicing learners' identity from the perspective of the FRDE as a roadmap for educational system.
\end{abstract}

Keywords: Identity, Globalization, Fundamental Reform Document of Education FRDE, Education

\section{Introduction}

Identity refers to "our understanding of who we are and who we think other people are" (Danielewicz, 2001, p. 10). Hyland (2010) remarked that identity is performance, but not merely narrating something. It is manifested in what people do. Hence, describing things that mismatch people's experiences does not give any information about their identities.

In the global village era people are becoming global customers of goods and data, thus the maintenance of a homogeneous identity becomes increasingly challenging. The cross-border nature of the flow of information make it even more difficult to retain unique and distinguish selves from other similar entities (Ariely, 2019).

In the Iranian context it is possible to easily spot the effects of the clash of values between the advocates of preserving/shaping learners' identity and globalization especially in the education system. The charter of Theoretical foundations of fundamental change in formal education in the Islamic Republic of Iran (2011) considers identity to have both individual and collective aspects. The Charter places identity alongside human, religious, national, ethnic, family, gender, global, and professional dimensions. 
The urge for a drastic change in educational policies is explicitly expressed in the introduction section of the Fundamental Reform Document of Education henceforth FRDE:

In spite of the commendable efforts made by education authorities during the past three decades to improve and conduct reforms in our education system, fortunately leading to some positive and effective outcomes, the system is still facing some serious challenges, the outcome of which is unfit to the prestige of the Islamic republic and does not meet the requirements of paradigm shift and social requirements. (FRDE, 2011, p.7).

Ayatollah Khamenei, the Supreme Leader of the Islamic Republic of Iran, instructs the decision making bodies of the country to change the educational paradigm. He believes that the authorities are not careful enough about the threats of UNESCO 2030 document as a symbol of globalization and a real threat to the identity of the next generation:

I am also a complainant of the Supreme Council of the Cultural Revolution; they should have taken care, they should not have allowed this to happen so that we would have to stop it and we would get into trouble (Khamenei, 2017).

He reminds them that the basis of all decisions about education is the norms of religion and avoiding the west as a blatant enemy:

This is the Islamic Republic; here, the basis is Islam, the basis is Qur'an; this is not a place where the corrupt, destructive lifestyle of the corrupt West can penetrate( Khamenei, 2017).

As a result, after about three decades and under the shadow of globalization, the supposed threat was responded with designing local regulatory plans such as the FRDE. In fact the policy makers' efforts aimed at meeting various ends among which preserving learners' identity is the most prominent one.

In 2011 the supreme council of Cultural Revolution devised a document as a prescription for the education system to be followed in different aspects including learners' identity. Rahbari, Belbasi, and Ghorbi (2015) stated that FRDE, the main regulatory educational document, does not see identity as a fixed concept but affected by the social circumstances, they suggested that the identity in the FRDE has three main aspects 1) Islamic 2) Iranian and 3) Modern

It is worth mentioning that although a number of scholars have investigated the FRDE (Mohammadzadeh \& Foroughi Abari, 2017; Rahbari et al., 2015) from different perspectives but to the best of researchers' knowledge, only few studies are conducted to clear the position of identity in the main educational document of the country which is considered to be the constitution of education in Iran. Thus this study employed a qualitative approach and used techniques based on content analysis and grounded theory to study how national identity is envisioned in the FRDE.

\section{Method}

In the present study, the researchers benefited from the FRDE, as the main educational document in Iran designed and legislated by the Supreme Council of Cultural Revolution based on the guidelines provided by Islamic revolution supreme leader, Ayatollah Khamenei to be implemented in every aspect of education in the Islamic Republic of Iran. Table 1 summarizes the main chapters of FRDE as follows: 


\section{Table 1}

The chapters of the FRDE

\begin{tabular}{ll}
\hline Chapters & Content \\
\hline Chapter 1 & Definition of key terms \\
Chapter 2 & Values Statement \\
Chapter 3 & Mission statement \\
Chapter 4 & Vision \\
Chapter 5 & Goals \\
Chapter 6 & Strategies \\
Chapter 7 & Operational objectives and strategies \\
Chapter 8 & Institutional framework and executive system of the FRDE \\
\hline
\end{tabular}

As table 1 depicts, the FRDE as the higher-order document to be implemented in the education system of Iran consists of 8 chapters.

To collect the required data as to learners' identity in the context of Iranian general education system, the researchers drew upon the FRDE as the main educational document aiming at changing educational paradigms approved in 2011 by the supreme council of Cultural Revolution and passed on by Ayatollah Khamenei in order to be enacted by the governing bodies of the Islamic Republic of Iran.

To begin, the researchers benefited from document analysis to trace the status of identity in the FRDE. The FRDE which includes 8 chapters was divided into 4 parts to be read and re-read by two independent researchers in order to spot cases pointing to identity. After each chapter was read meticulously, the independent researchers met on a weekly basis to check the appropriateness of the assigned codes and the content. On the whole, it took 8 weeks to meticulously read and re-read the chapters and as many codes as spotted vis a vis to the concept of identity were assigned. During the collection of data, researchers happened to disagree on certain cases which were sent to a third party to comment upon their appropriateness.

\section{Data Analysis Procedure}

In order to analyze the data, content analysis was run by the researchers to extract and codify the points which were raised in the FRDE regarding practicing learners' identity. In so doing, data analyses were carried out with the help of MAXQDA software. The main advantage of content analysis is that it helps in data collected being reduced and simplified (Krippendorff, 2009). In the current study, the REDE was divided into 4 parts, each one including two chapters. Each part was given a name and inserted into the software. Having organized the data in MAXQDA, the researchers commenced the coding and reducing process which comprises 3 distinct stages, namely, open coding, axial coding and finally selective coding to synthesize concepts and bring the categories together into an overarching theory or model (Strauss \& Corbin, 1998). In fact, out of coding procedure for FREDE, as many as 331 codes were created which were reduced to 16 categories and 6 themes. 
In this study the dependability procedures were accomplished in 3 steps: first, in order to assure that the codes concord the nature of the content, the researchers continuously compared the data with the given codes. Second, besides the two researchers, nearly twenty percent of the data were cross-checked independently by two more coders in terms of stability and consistency of the assigned codes. More than $80 \%$ of consistency was observed among the coders. Miles and Huberman (1994) suggest that an IRR of $80 \%$ agreement between coders on $95 \%$ of the codes is sufficient agreement among multiple coders. According to Creswell and Miller (2000), credibility takes into account the accuracy of findings from the viewpoint of researchers and external auditors. as a result, the researchers asked a colleague to review the whole study. Therefore, at the third and final step, the genuineness of the data was double-checked by a person other than the researchers who did not know them. He was asked to review the whole study. Finally, the external auditor accepted that the data are genuinely gathered and interpreted.

\section{Results and Discussion}

Due to the space limitations, the authors could not present the whole sentences extracted from FRDE in this article, therefore each related section of FRDE is presented here and can be observed in detail by referring to the original document.

The results for the points that are discussed in the FRDE as to practicing learners' identity are as follows:

\section{The Nationwide}

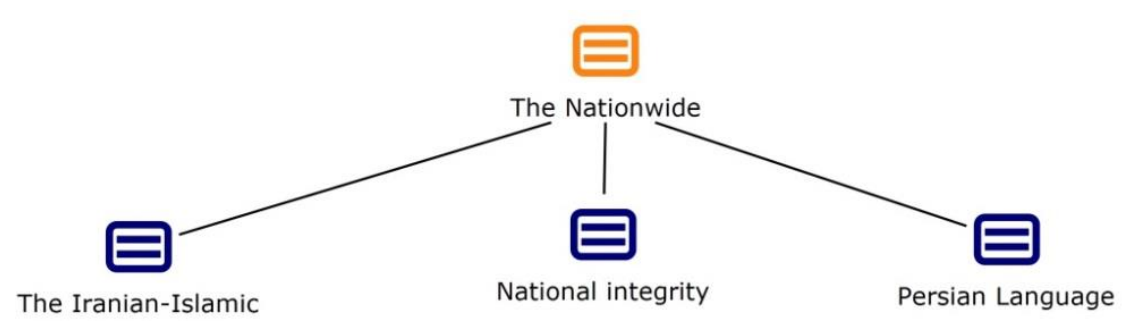

Figure1. The Nationwide and its related categories in FRDE

\section{National integrity}

The authors of the FRDE as a higher-order document have tried to cover a wide range of topics related to identity but this attempt is seemingly calibrated to the Islamic Republic of Iran's paradigms and patterns. After analysis of FRDE for the topics raised under the title of identity five main themes were distinguished as the most prominent aspects, these include: The Nationwide, The Social, The Islamic, The Individual and The Global themes; each one has a number of subcategories which give details about direct and indirect references to the concept of identity in the document. In line with these findings, Rahbari et al. (2015) state that the concept of identity is not defined as a fixed and predetermined concept, but as the outcome of one's effort and success, and to some extent affected by the social circumstances. 
Apparently, FRDE sees no opposition between the individual and national interests. It implies that individual and social interests are interwoven and one depends on the other. The document seeks to deepen this perspective among Iranian students.

Examples:

Chapter two; value statement, article 18: Taking into account both individual and social interests within the confines of national interests.

Chapter two; Values statement; article 19: Preserving national solidarity and social integrity through an emphasis on joint Islamic-Iranian identity.

Chapter seven; operational objectives and strategies; Strategy 1-7: Establishment of mechanisms for social cohesion, national solidarity and revitalization of the honorific Islamic-Iranian identity among the students and teachers with an emphasis on teaching and performing the national anthem and flying the Islamic Republic of Iran's national flag at all Iranian schools.

\section{Persian Language}

According to article 15 of the Islamic Republic of Iran's constitution, Persian is the official language of the country; surprisingly, FRDE is silent about the Persian language except for the only instance where it entails to promote the inclination to Persian language and literature as a lingua franca. In fact, Persian is like an invisible loop welding the learners' shared identity (Fallah, 2007). It seems that Persian is not only considered as a great help for preserving the learners' identity within the boarders, but also is seen as a means for the realization of the supposed regional superiority in different facets based on the designed vision of the country in 2025 .

\section{Example:}

Chapter 2; value statement; article 21: Strengthening the tendency towards Persian language and literature as a lingua franca.

\section{Iranian-Islamic}

Iranian-Islamic is one of the most cited aspects of FRDE and considered to be the main tool for building Modern Islamic civilization. For instance, the Ministry of Education of the Islamic Republic of Iran (2011) introduced Strategy 1-5 dealing with teaching foreign languages. That strategy was a "provision of foreign language education within the optional (Core-elective) section of the curriculum framework by observing the principle of stabilization and enforcement of the Islamic-Iranian identity". Without a doubt in the eyes of the revolutionary policymakers even teaching a foreign language is meant to strengthen the "Islamic-Iranian identity" of the students.

\section{Examples:}

Chapter two; Value statement; article 5: Pavement of the ground for acquiring the basic qualifications with an emphasis on joint Islamic-Iranian and revolutionary characteristics, in line with continuous evolution and edification of the student's identity at the individual, family, and social dimensions.

Chapter seven; operational objectives and strategies; Strategy 1-5: Provision of foreign language education within the optional (Core-elective) section of the curriculum Framework by observing the principle of stabilization and enforcement of the Islamic-Iranian identity 
Chapter seven; operational objectives and strategies; Strategy 2-5: Establishment of necessary mechanisms for strengthening the Islamic-Iranian style and etiquettes of life in all educational domains as a prevailing approach in designing, devising, and the implementation process of curriculum development.

The Social

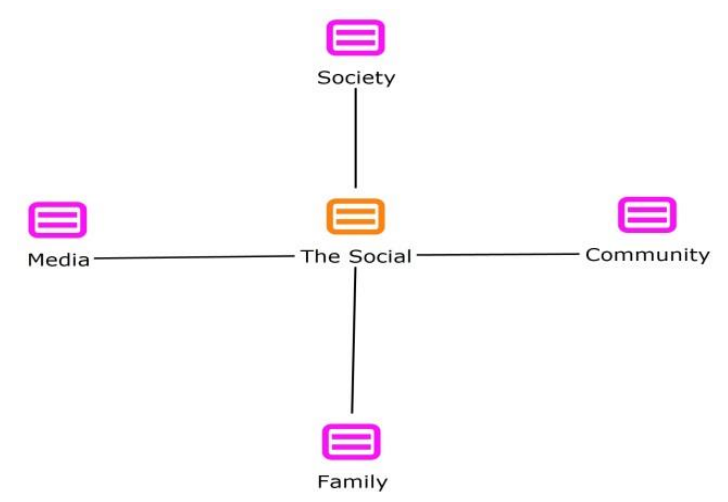

Figure2. The Social and its related categories in FRDE

\section{Society}

The second main theme regarding the fingerprints of identity in FRDE is the "Social" aspect. As it was mentioned before identity is an insoluble subject while society is one of the indispensable contributing ingredients in its formation, evolution, and consolidation. The document denies the sovereignty of profit in social relations and in contrast prescribes the recognition of humanitarian principles as the backbone of social interactions. Thus it intelligibly tries to direct the educational programs towards meeting these ends. It is worth mentioning that the type of society that is recognized by FRDE is the promising Islamic society which is ruled according to Islamic jurisprudence and therefore the shaped identity is defined within the value system of such society (culture).

\section{Examples:}

Chapter one: Definition of key terms; Identity: Identity is not a fixed and predetermined concept but the outcome of one's effort and success and to some extent affected by the social circumstance.

Chapter seven; operational objectives and strategies: gain competence to face the social and political changes accountably and wisely through understanding the social and political concepts and "respect to the law" and by maintaining national unity and rapport.

\section{Community}

FRDE believes that the communities and institutions must act as role models and try to navigate the students' attitudes towards the world. They should help the students in depicting an ideological approach rooted in the Islamic norm system as a part of a bigger picture.

The document assigns the communities and institution such as home, schools, mosques, cultural centers as well as the active societal agents like teachers, clergies, and instructors to play their roles in the process of shaping the students' identity. It is assumed that the path of identity formation in today's 
societies is through home and school. In fact, children and adults spend a lot of time in the formal education system in which they are subjected to various trainings (Alavi Moghaddam \& Dāvarpanāh, $\underline{2014})$.

\section{Examples:}

Chapter seven; operational objectives and strategies; Strategy 7-1: Pavement of the ground for schools to role model as focal points for acquisition of local community experience and demonstration of Islamic society and Hayate Tayyebah by the delegation of authority and responsibility to them and standardization of all school-related components and index.

Chapter seven; operational objectives and strategies: make attempts to defend the national dignity and authority and with accountability and an edification-seeking sprit, and communicative skills in their family and social lives (at national and global levels) compatible with the Islamic norm system.

\section{Media}

These days media is a "source of information" for a huge number of people, thus can have a great share in shaping the identity structure of every individual in a society.

The FRDE looks for boosting the influence of media and increasing its efficacy for maximum impact on the education process. The document recognizes the status and the role of media on the process of shaping the students' identity and at the same time tries to find out a solution for controlling what it calls undesirable effects, expressing similar ideas, Hashemi (2015) mentions that by reviewing the paragraphs of FRDE related to media, we can boldly say that media literacy is as important as the ability to read and write because the influence of the media has greatly expanded in the world.

\section{Example:}

Chapter two; Value statement; article 17: Being aware of the status and role of the media and communication technologies and their intelligent application and active and informative engagement to control and prevent their undesirable consequences.

Chapter seven; operational objectives and strategies; Strategy 4-1: Education and promotion of family management in proper utilization of the media at home in line with the objectives of the country's general formal education system.

Chapter seven; operational objectives and strategies; Strategy 8-9: Effective interaction with cultural and social centers and making use of the media's capacity, especially the national media (Islamic Republic of Iran Broadcasting) to elucidate the status of the country's general formal education system in the production of social and cultural capital and to avoid underestimating its role in the country's future destiny from an Islamic education perspective.

\section{Family}

FRDE insists on empowerment and consequently partnership of the families in educational procedures. The document does not see the families as passive agents in training the new generation but believes that the identity of the family has the greatest effect on the formation of each individual identity.

Examples: 
Chapter two; Value statement; article 5: Evolution and edification of the student's identity at the individual, family, and social dimensions.

Chapter two; value statement; article 14: Promotion of the status and developmental role of the family and its effective partnership in the country's general formal education system.

Chapter five; Goals; article 2: Promotion of the role of the general formal education system and the family in the country's progress and development, dissemination and edification of the public culture and paving the ground for scientific strength and reference, the evolution of Islamic-Iranian civilization in line with the realization of the global Mahdavi Just Community with an emphasis on gaining religious, political insight, deepening of knowledge, commitment to ethical values, loyalty to the Islamic Republic of Iran's ruling system.

Chapter five; Goals; article 5: Enhancement of public participation and effectiveness especially the family's role in the edification of the country's general formal education system.

\section{The Islamic}

The Islamic aspect of the identity, with no surprise can be traced in all other forms of identity sketched by the policymakers in this document. This category includes "Religion and Ideology, Islamic Revolution, Islamic dress code and Mahdaviat". The layer of Islamic identity can be identified in the document with components such as Monotheism, Islamic principles and teachings, Hayate Tayebe, justice, Mahdaviat and Intizar (Period of waiting), Promotion of virtue and Prevention of vice, Velayate-Faqih, Hijab and chastity.

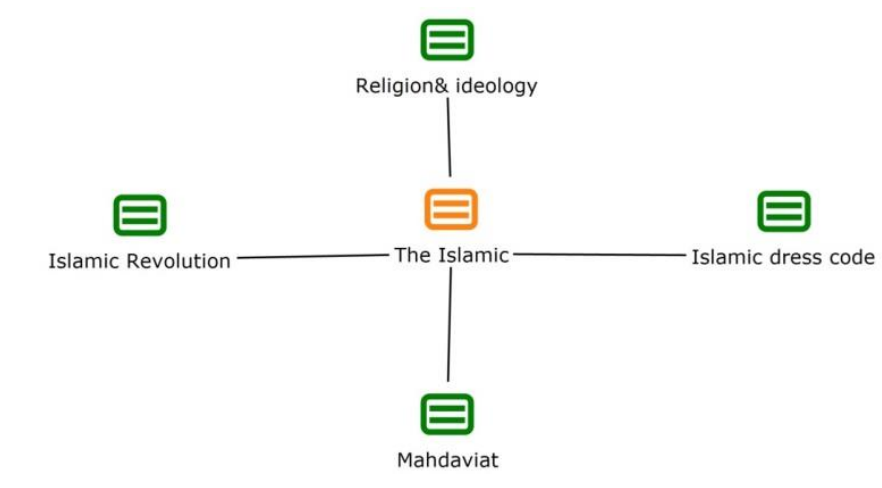

Figure3. The Islamic and its related categories in FRDE

\section{Religion and ideology}

Religion and ideology are two essential interlaced issues in shaping the identity of the students from the view point of the formal education system and perhaps they can be boldly called the backbone of FRDE as the constitution of the education system in the Islamic Republic of Iran. In this framework the supreme leader's words, Mohammadian Islam, Islamic norm system and its spiritual recommendations are the main concerns in shaping students' identity and orders of the Quran and prophet's Sunna are preferred over all instructions. FRDE highlights the teachers' role in shaping the desired identity and insists on training teachers who are faithful to Islamic ideology and truly believe in its intellectual system. 


\section{Examples:}

Chapter one: Definition of key terms; Islamic norm system: The Islamic norm system is comprised of the rudiments and values based on or compatible with the original Mohammadian Islam (Prophetcondoned reading of Islam), including a hierarchy of values, applicable to all aspects of life; since Islam addresses all social, individual, worldly, hereafter world, material and spiritual dimensions of life (negating secularism); although some of these dimensions have been discussed in general and some others have been discussed in detail.

Chapter five; Goals; Goal one: Fostering monotheist individuals who have faith in God and believe in the hereafter world, who are committed to the responsibilities towards God, themselves, others, and nature.

\section{Islamic Revolution}

In Iran the Islamic revolution as the main paradigm shift is considered to be the main reason for compiling the documents such as the FRDE and changes in high school English textbooks. Theorizing the idea of renovating the great Islamic civilization is rooted in the thoughts of the supreme leader of the revolution, Ayatollah Khamenei, and is considered as one of the cornerstones of the desired identity depicted by the late founder of Islamic government in Iran, Ayatollah Khomeini. As a result making students committed to the values of revolution is the first mission of the education system in the Islamic system.

\section{Examples:}

Chapter four; vision: Forming their Islamic- revolutionary identities

Chapter four; vision; school vision in 2025: Demonstrates a rich Islamic revolutionary culture in relationship with the creator of the world, oneself and the other, especially commitment...

\section{The Islamic dress code}

FRDE frequently uses the word Hijab which is an Islamic terminology and a symbolic Identity indicator especially for females.

The document assigns the education system to plan for promotion of "Hijab" and religious viewpoints. It usually puts the word Hijab next to the moral values such as virtue and modesty.

FRDE ascribes the formal education system to use the capacity of educational plans, curriculum and media for promotion of Hijab while the role given to the family as the main core in shaping students' identity is undeniable. It seems that students' appearance as the visible side of their identity is of a high importance for policymakers; they consider it as the outcome of their prescribed plans which are designed based on the Islamic norm system and an indicator for measuring their success in bringing about the expected reforms.

\section{Examples:}

Chapter seven; operational objectives and strategies; Strategy 3-2: Taking proper measures in recruiting, training and using qualified, committed human resources who observe modesty, virtue, and Hijab at educational environments. 
Chapter seven; operational objectives and strategies; Strategy 3-6: Planning for intellectually preparing the students to truly and willingly accept modesty, virtue and Hijab and act thereon by imparting the Islamic view to them.

\section{Mahdaviat (waiting culture)}

Belief in the Mahdavi society is seen as an ideal life model in various parts of the document, FRDE seeks to reinforce this view and its increasing impact on students' personalities. In this view, the identity of students must be influenced and prepared to gain the required prerequisites of ruling the world after "Zohour" (reappearance). Based on Shia Muslim beliefs and the concepts such as fighting against injustice and oppression should be explained to students in their curricula and books.

\section{Example:}

Chapter five; Goals: Goal 2: Paving the ground for scientific strength and reference, the evolution of Islamic-Iranian civilization in line with the realization of the global Mahdavi Just Community with an emphasis on gaining religious, political insight.

\section{The Individual}

In the realm of individual differences, gender and minorities are recognized as two main indicators of individual identity. The concept of justice for the recognized differences in the Islamic society such as the differences between men and women, the religions mentioned in the constitution, vernaculars and dialects used by the Iranian ethnic groups and finally physical and IQ differences are discussed in the document. In the area of individual empowerment, the document emphasizes on strengthening students' physical and mental health and highlights the development of individual skills and qualities such as being responsible. FRDE requires the education system to empower the students by participating them in different executive processes based on their interests and abilities; it also seeks to educate a generation that is able to govern the society by using their potentials for solving the problems with confidence and honesty in future.

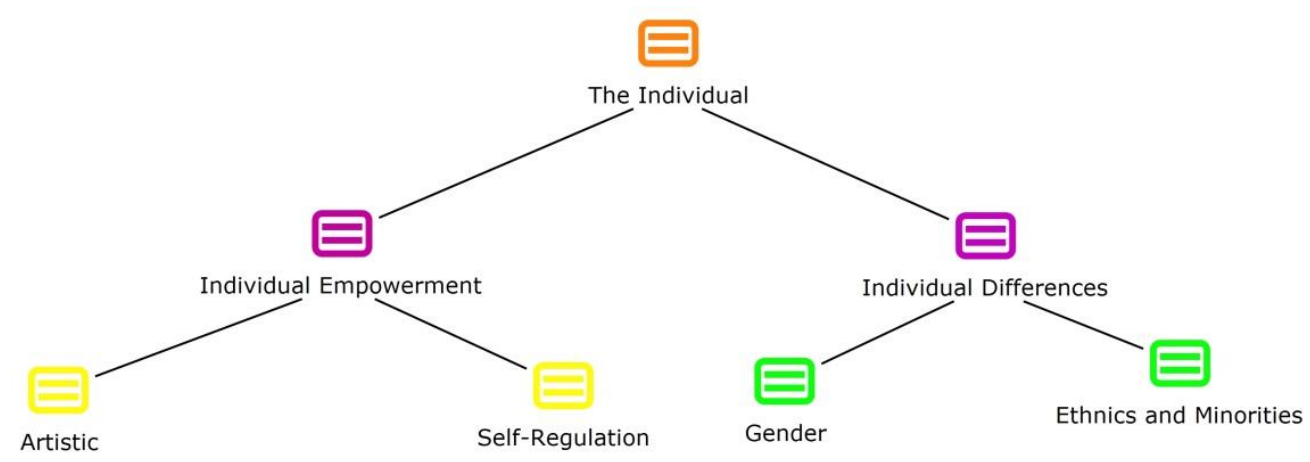

Figure4. The individual and its related categories in FRDE

\section{Individual differences}

Examples: 
Chapter seven; operational objectives and strategies; Strategy 1-1 (e): Further attention to individual differences among students especially gender, urban and rural differences

Chapter one; definition of key terms: Basic competencies are a set of individual and collective qualities and qualifications applied to all dimensions of identity (rational, emotional, willful \& practical).

Chapter four; vision: ... and take into account their individual characteristic.

Chapter seven; operational objectives and strategies; Strategy 5: Provision and development of equal learning opportunities both for male and female students in various areas of the country that take into account their characteristics and differences.

Chapter four; vision; school vision in 2025: Enjoys the capacity of embracing individual differences, exploring and guiding different instinct talents and meeting the students' needs and interests in line with the framework of the Islamic norm.

\section{Gender}

Examples:

Chapter two; value statement: General and compulsory aspects and qualitative equity by observing and respecting individual, gender, cultural and geographical differences.

Chapter seven; operational objectives and strategies; Strategy 1-1 (e): Further attention to individual differences among students especially gender...

Chapter two; value statement: Article 16: Educational and developmental equity at quantitative, general and compulsory aspects and qualitative equity by observing and respecting individual, gender, cultural and geographical differences.

\section{Ethnics and minorities}

Examples:

Chapter two; value statement; article 1: The religious minorities stipulated in the constitution shall act according to the relevant rules and regulations.

Chapter two; value statement; article 16: Educational and developmental equity at quantitative, general and compulsory aspects and qualitative equity by observing and respecting individual, gender, cultural and geographical differences.

\section{Individual Empowerment}

\section{Example:}

Chapter one; definition of key terms: To reach this stage of preparation for continuous evolution and edification of the students' identities (with an emphasis on shared humane, Islamic and Iranian dimensions) while taking into account the individual and idiosyncratic qualities.

\section{Artistic}

\section{Example:}

Chapter seven; operational objectives and strategies: Acquire the required capabilities to create cultural and artistic works by appreciating and aesthetic understanding of God's creations and the man's artistic works by understanding the cultural and cross--cultural concepts, and by using their own 
imagination power; and those who make efforts to preserve and promote the cultural, artistic and civilization heritage of the country at national and global levels, based on the Islamic norm system (Goals 1, 4, 5, 2, 8).

\section{Self-Regulation}

\section{Example:}

Chapter four; vision; school vision in 2025: Is based on a participatory management approach open to critics.

\section{The Global}

The document aims at creating an educational system that can be presented as a model at the regional and global levels. FRDE tries to distinguish the identity of those who are studying under the paradigms of the Islamic Republic of Iran from other schools of thought.

Two categories of "Self Determination" and "Intercultural Interactions" confirm the abovementioned assertion. As the document implies "the Islamic government must concentrate on 2025 vision in which the country is expected to promote to the highest economic, scientific and technological position at the regional level with an Islamic, revolutionary identity to motivate the Islamic world through constructive and efficient interaction at the international arena". The education system tries to impact the students' identity and lifestyle through guiding them to determine themselves as a self-reliant nation and faithful to the values of the Islamic ideology.

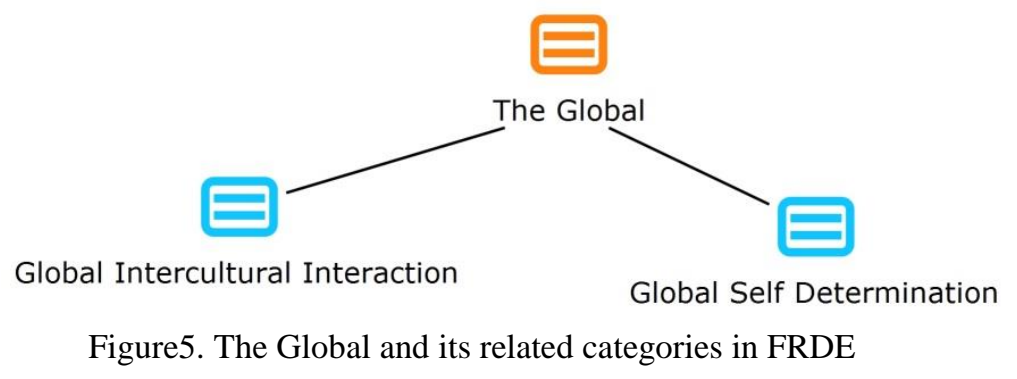

\section{Global self-determination}

\section{Example:}

Introduction: In light of such a sublime human capital, humanity shall be prepared for the realization of a global reign for perfect mankind and under such governance, the talents and potentials of mankind shall boom towards perfection.

\section{Global Intercultural Interaction \\ Examples:}

Chapter seven; operational objectives and strategies; Strategy 11-11: Active participation in international interactions with a priority on the Islamic world and sharing the successful local experiences at international scientific and academic communities.

Chapter two; value statement; Article 22: Preservation of Islamic-Iranian culture through a conscious assessment and critical interaction with other cultures based on an Islamic norm system. 


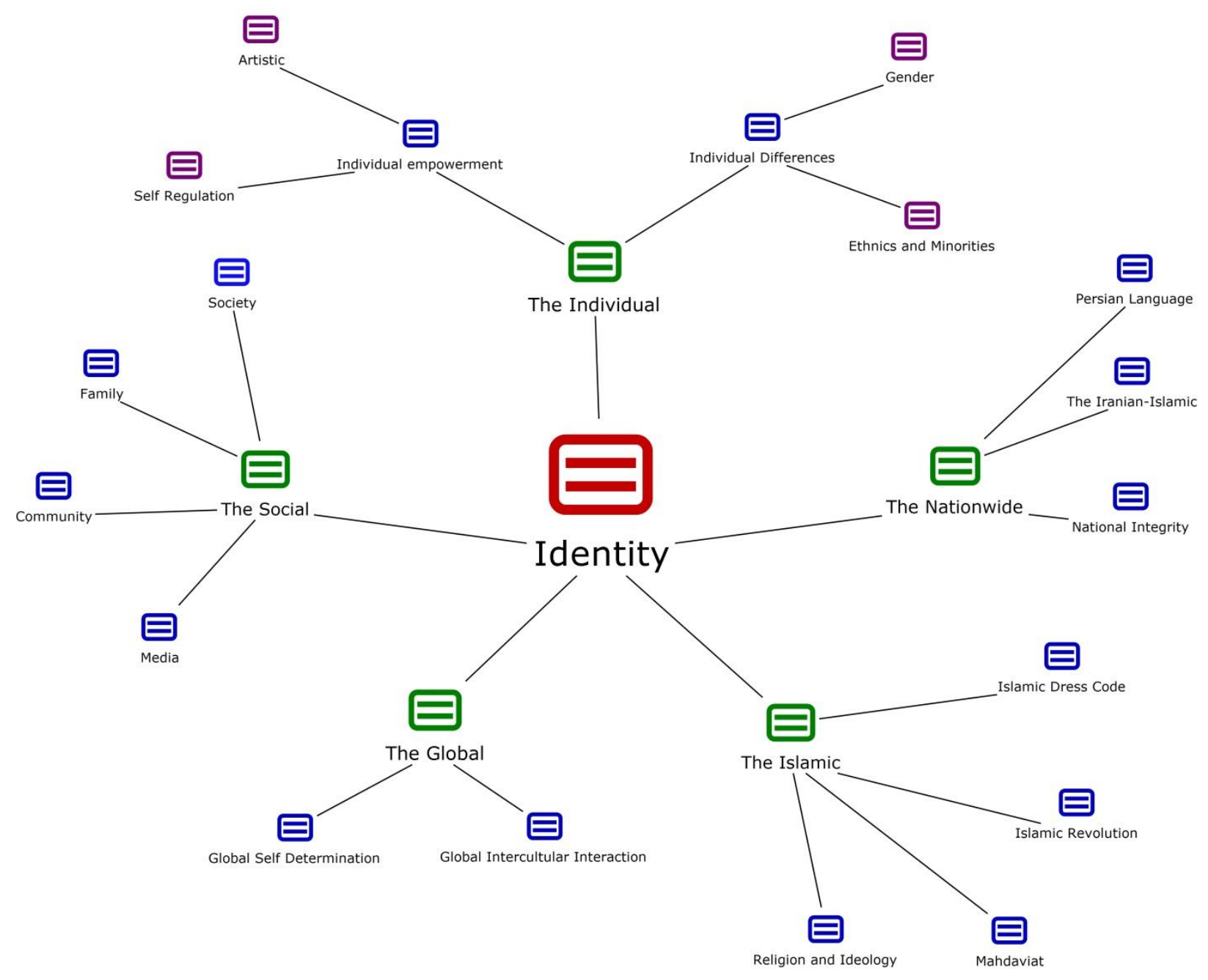

Figure6. Model of Practicing Identity in FRDE

\section{Conclusion}

As the content analysis of the FRDE showed, identity is a real concern for the policy makers; this concept is presented through direct and indirect statements in the whole document but through an ideological Lenz. All five emerging themes a) The Nationwide b) The Islamic c) The Social d) The Individual and, e) The Global are defined within the framework of Islamic norm system and aimed at forming the type of shared identity called Hayate Tayebe (Good life) as the product of the education process.

The content analysis of the FRDE showed identity is a real concern for the policy makers; this concept is presented through direct and indirect statements in the whole document but through an ideological Lenz. All five emerging themes a) the Nationwide b) the Social c) the Islamic d) the Individual and, e) the Global are defined within the framework of Islamic norm system and aimed at forming the type of shared identity aimed at what is called Hayate Tayebe (Good life) as the product of the education process. The results of this study help the policymakers and other stakeholders to review their policies on practicing identity in the Iranian educational context. As such it is hoped that the study paves the way for more comprehensive policies and guidelines in the upcoming, reviewed versions of the FRDE in the 
near future. Teachers and student-teachers can also be among those who benefit from the results of this research as it may lead to raising awareness among them regarding the desires of the formal education system.

Conflict of interest: The authors state no conflict of interest in the study.

Financial sponsor: The authors acknowledge that they have not received any financial support for all stages of the study, writing and publication of the paper.

\section{References}

Alavi Moghaddam, B., \& Dāvarpanāh, Z. (2014). Content analysis of national identity components in French education textbooks at guidance school, high school and pre-university levels. Educational Innovations, 13(4), 117-140.

Ariely, G. (2019). The nexus between globalization and ethnic identity: A view from below. Ethnicities, 19(5), 763-783.

Creswell, J. W., \& Miller, D. L. (2000). Determining validity in qualitative inquiry. Theory into practice, 39(3), 124-130.

Danielewicz, J. (2001). Teaching selves: Identity, pedagogy, and teacher education: Suny Press.

Fallah, M. (2007). The role of Persian language in the national unity of Iran. researches on mystical literature (gowhar-i-guya), 1(4), 131-164.

Hashemi, S. (2015). Review of Media Role in Educational System of Document on Fundamental Reforms in Education: Emphasis on Necessity of Media Literacy Education. Rasaneh, 25(4), 5-18.

Hyland, K. (2010). Community and individuality: Performing identity in applied linguistics. Written communication, 27(2), 159-188.

Khamenei. (2017). Retrieved from https://english.khamenei.ir/

Krippendorff, K. (2009). The content analysis reader: Sage.

Miles, M. B., \& Huberman, A. M. (1994). Qualitative data analysis: An expanded sourcebook: sage.

Mohammadzadeh, S. M., \& Foroughi Abari, A. A. (2017). Eductional foundation of sanctimonious life in development prepectivisation document (the national curriculum document) from a critical point of view. Research in Curriculum Planning, 14(52), 1-11.

Rahbari, M., Belbasi, M., \& Ghorbi, S. M. J. (2015). National identity in the document of fundamental transformation of the education in IRI. National Studies, 16(1), 45-66.

Strauss, A., \& Corbin, J. (1998). Basics of qualitative research techniques: Citeseer. 